https://doi.org/10.36909/jer.v9iICRIE.11631

\title{
Influence of Tension Stiffening and Cracked Shear Modulus Models on Non-Linear Analysis of High Strength Fibrous Reinforced Concrete Slabs
}

\author{
Ahmed Asaad Yaseen * and Ayad A. Abdul-Razzak
}

*College of Engineering, University of Mosul, Iraq

*Email: eng.ahmed.asaad91@gmail.com; Corresponding Author.

\begin{abstract}
In the present study, new models are proposed for tension stiffening and cracked shear modulus to study their effect on the response of the slab. These models are used in the nonlinear analysis of High Strength Steel Fiber Reinforced Concrete (HSSFRC) slabs. The suggested models have multiple shapes depending on the curvature factor, these models are compared with the wellknown formulas used in previous studies and great agreements are achieved. The Serendipity "eight-node" element type has been adopted for representing the concrete and layered approach is used to simulate the concrete elements and a smeared layer approach is used to represent the steel reinforcement. The concrete compression behavior is modeled using strain hardening plasticity method, the first two stress invariants of the yield condition is used. For finite element analysis, a computer program coded in Fortran 90 is developed and used for performing nonlinear analysis on the slabs. In order to check the validity of the current models, many actual results for testing slabs "in the laboratory" are compared with the results from the present study and a great agreement is achieved. All studied slabs were simply supported from four sides and loaded with concentrated load at the middle of the slab, but slab S5 is simply supported by two opposite parallel sides with line load parallel to the supports at the middle of the span of the slab. For the curvature factors $\left(B_{t}, B_{g}\right)$ it is found that the values $\left(B_{t}=0.005-0.5, B_{g}=0.001-0.05\right)$ give the best simulation for the slab. The effect of tension stiffening model is more than the effect of cracked shear modulus model and there is an interaction between tension stiffening
\end{abstract}


and cracked shear modulus models.

Keywords: Cracked shear modulus; Finite element; High strength concrete; New constitutive relationships; Reinforced concrete slabs; Steel fiber; Tension stiffening

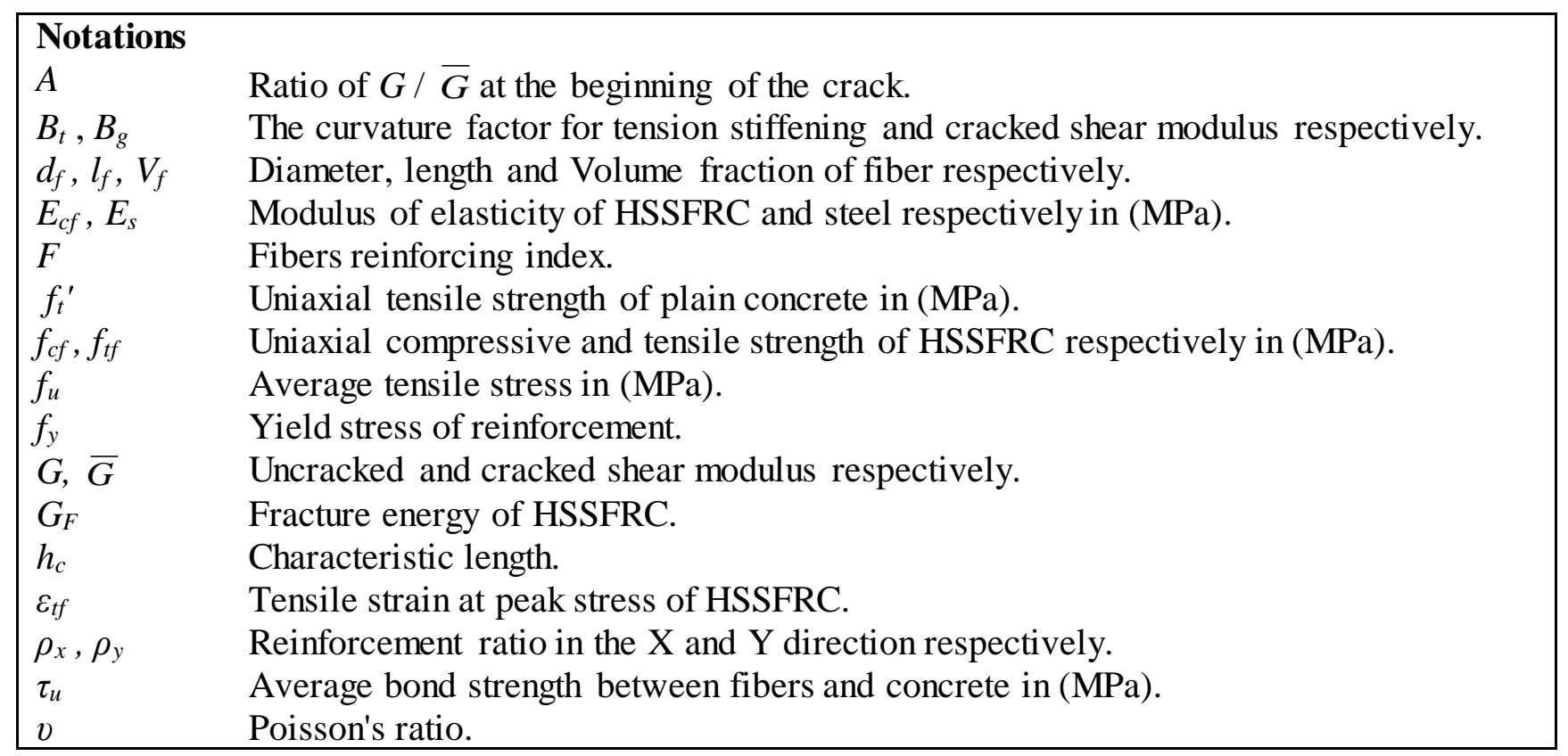

\section{GENERAL INTRODUCTION}

The slabs are the first structural members subjected to the loads and transfer these loads to the columns and beams, therefore it is important to study the slab's behavior under increasing loads up to the failure load. Using of high strength concrete has developed and increased to reduce the cross sections of the members and that let to reduce the weight of the building and get a larger space of the areas, therefore using high strength concrete has a structurally and economically benefits (Mohammed, 2011). In another hand, the brittleness of high strength concrete is the main dis advantage, and one of the methods to overcome this issue is by adding steel fiber to the concrete and this also will ensure high ductility during post crack stage in tension, and post peak stage in compression (Lee., Oh., \& Cho., 2015). So, the benefits of adding fibers to the concrete are to improve its tensile strength, ductility, durability, toughness and flexural strength (AbdulRazzak \& Mohammed, 2011).

In this paper, the influence of the tension stiffening and cracked shear modulus models is discussed and taken in consideration by proposing new models for them and study their effect in 
the nonlinear analysis of the studied slabs. The studied slabs which are experimentally tested in the laboratory by the researchers in the references (Al-sinjari, 2014; Ragab, 2013; Yaseen, 2006; Zaki, Ragab, \& Eisa, 2013) are modelled and analyzed in the present study using a coded program in FORTRAN 90 which is used also in reference (Abdul-Razzak, 1996), this program is modified to analyze high strength fiber reinforced concrete. The slabs characteristics and dimensions are listed below. The result from this study is compared with the experimental results in the mentioned references and great agreement is achieved in term of load deflection curve, failure load and crack pattern.

\section{MODELLING OF MATERIALS}

The main scope of any theoretical study is predicting the response and strength of the member subjected to increasing load until the failure of the member. To achieve this goal, it is very important to study the material properties of the studied member which is HSSFRC, these properties should be studied and modeled correctly depending on experimental results.

\section{UNIAXIAL TENSILE STRENGTH OF HSSFRC}

In the present study, the behavior of HSSFRC in tension can be divided into two stages, which are pre peak stage and post peak stage as shown in Figure 1.

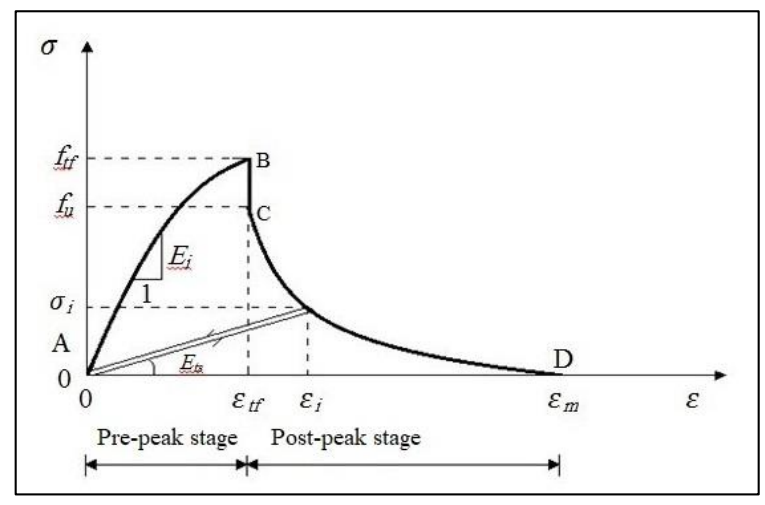

Figure 1 uniaxial stress-strain relation in tension (Abdul-Razzak \& Mohammed, 2011) 


\section{PRE-PEAK STAGE}

To simulate this stage, the following suggested equation is used and a great agreement with experimental values in reference (Lin, Huang, Lee, \& Hsu, 2008) is achieved with index of determination equal to $99 \%$.

$$
\sigma_{i}=f_{t f} \sin \left(\frac{\pi}{2} \frac{\varepsilon_{i}}{\varepsilon_{t f}}\right)
$$

\section{PPOST-PEAK STAGE}

The path BCD represents the post-peak stage in uniaxial tensile behavior as shown in Figure 1. The tensile behavior after cracking of concrete depends on the pullout action of fibers. The shear strength between the steel fibers and the concrete $\tau_{u}$ can be obtained from the following equation which is used in reference (Mohammed, 2011):

$$
\tau_{u}=0.85 f_{c f}^{0.6}+2.4 F^{0.6}
$$

So, the average tensile stress $f_{u}$ is calculated from the following equation:

$$
f_{u}=0.41 \tau_{u} F
$$

where $\mathrm{F}$ is the fiber reinforcing index which is equal to $(\mathrm{Vf} * \mathrm{lf}) / \mathrm{df}$

A nonlinear stress strain behavior is assumed in this study to represent the post-peak stage as shown in Figure 2 (path $\mathrm{CD}$ ). The proposed nonlinear equation has a curvature factor $B_{t}$ can

affect the nonlinearity of the equation, when this value increased the nonlinearity of the equation will decrease and approach to the linear equation as shown in Figure 2.

$$
\begin{aligned}
& \sigma_{i}=f_{u} \frac{B_{t}-\mathrm{B}_{t} * \mathrm{X}}{B_{t}+X} \\
& X=\frac{\varepsilon_{i}-\varepsilon_{t f}}{\varepsilon_{m}-\varepsilon_{t f}}
\end{aligned}
$$

Where $\left(B_{t}\right)$ represent the curvature factor of the equation as shown in Figure 2. 
The following suggested equation is adopted to get the value of $\varepsilon_{t f}$, and this equation shows great agreement with experimental test result in reference (Lin et al., 2008) with 95.5\% index of determination.

$$
\varepsilon_{t f}=\frac{11 F+3 f_{t f}}{10^{5}}
$$

the maximum tensile strength $f_{t f}$ can be obtained from equation (7). A great agreement with $72.84 \%$ index of determination is achieved with experimental results in references (Abbass, Khan, \& Mourad, 2018; Koksal, Altun, Yigit, \& Sahin, 2008; Song \& Hwang, 2004).

$$
f_{t f}=0.3 F f_{t}^{\prime}+2.8 F+f_{t}^{\prime}
$$

In some studies, the value of $f t^{\prime}$ is not measured, so the value of $f_{t f}$ can be calculated depending on the compressive strength of the concrete using the following suggested equation.

$$
f_{t f}=2.94 F+0.08 f_{c f}
$$

Acceptable agreement is achieved with experimental results in references (Abbass et al., 2018; Musmar \& Rjoub, 2007) with 65.62\% index of determination.

$$
\begin{gathered}
G_{F}=\int_{0}^{\delta} \sigma(\delta) d \delta=\int_{\varepsilon_{t f}}^{\varepsilon_{m}} \sigma_{i} h_{c} d \varepsilon \\
G_{F}=h_{c} f_{u} \int_{\varepsilon_{t f}}^{\varepsilon_{m}} \frac{B_{t}-\mathrm{B}_{t} * \mathrm{X}}{B_{t}+X} d \varepsilon \\
G_{F}=h_{c} *\left(\ln \left(\varepsilon_{m}-\varepsilon_{t f}+B_{t} * \varepsilon_{m}-B_{t} * \varepsilon_{t f}\right) *\left(f_{u} * B_{t} * \varepsilon_{m}-f_{u} * B_{t}^{*} \varepsilon_{t f}+f_{u} * B_{t}^{2 *} \varepsilon_{m}-f_{u} * B_{t}^{2 *} \varepsilon_{t f}\right)-\ln \left(B_{t}^{*} \varepsilon_{m}\right.\right. \\
\left.\left.-B_{t} * \varepsilon_{t f}\right) *\left(f_{u} * B_{t} * \varepsilon_{m}-f_{u} * B_{t} * \varepsilon_{t f}+f_{u} * B_{t}^{2 *} \varepsilon_{m}-f_{u} * B_{t}^{2 *} \varepsilon_{t f}\right)-f_{u} * B_{t} * \varepsilon_{m}+f_{u} * B_{t}^{*} \varepsilon_{t f}\right)
\end{gathered}
$$

This equation is achieved by completing the integration. After substituting the values of $h_{c}, f_{u}$, $G_{F}, \varepsilon \mathrm{tf}, B_{t}$ in equation (11) and solving the equation, the value of $\varepsilon_{m}$ can be calculated.

$$
h_{c}=\sqrt{d A}
$$

Where $G_{F}$ is fracture energy of high strength steel fiber concrete.

$d A$ is the area represented by Gauss point.

$h_{c}$ is the characteristic length of the concrete 


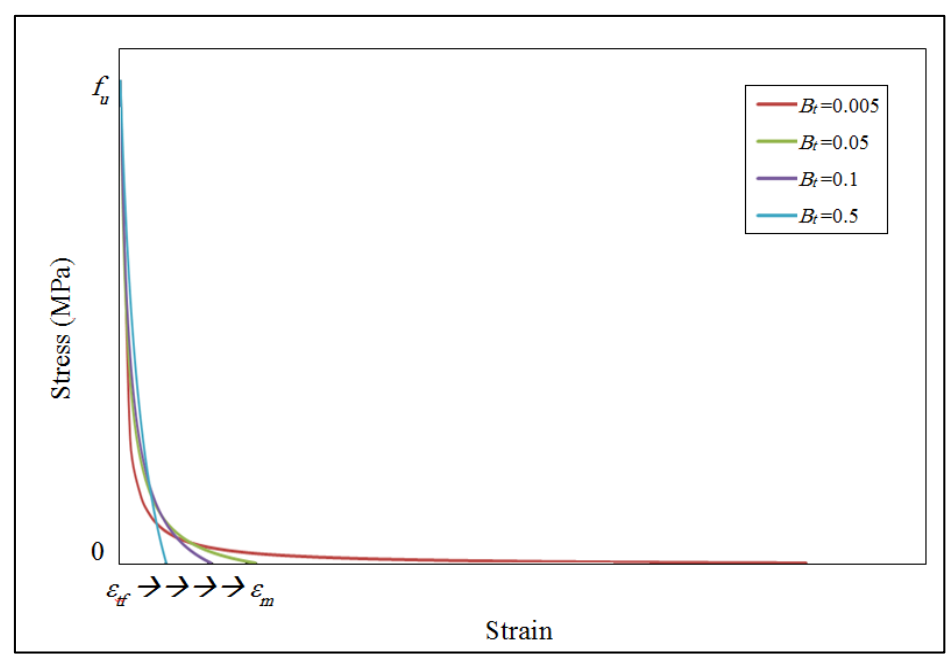

Figure 2 The effect of curvature factor on the shape of stress strain curve in tension for HSSFRC in post peak stage.

It is important to compare the suggested model for tension stiffening with the models suggested by another researchers. Figure 3 shows the comparison between present model (with $B_{t}=0.5$ ) and the models in references (Abdul-Razzak, 1996; Mohammed, 2011) and a good agreement is achieved.

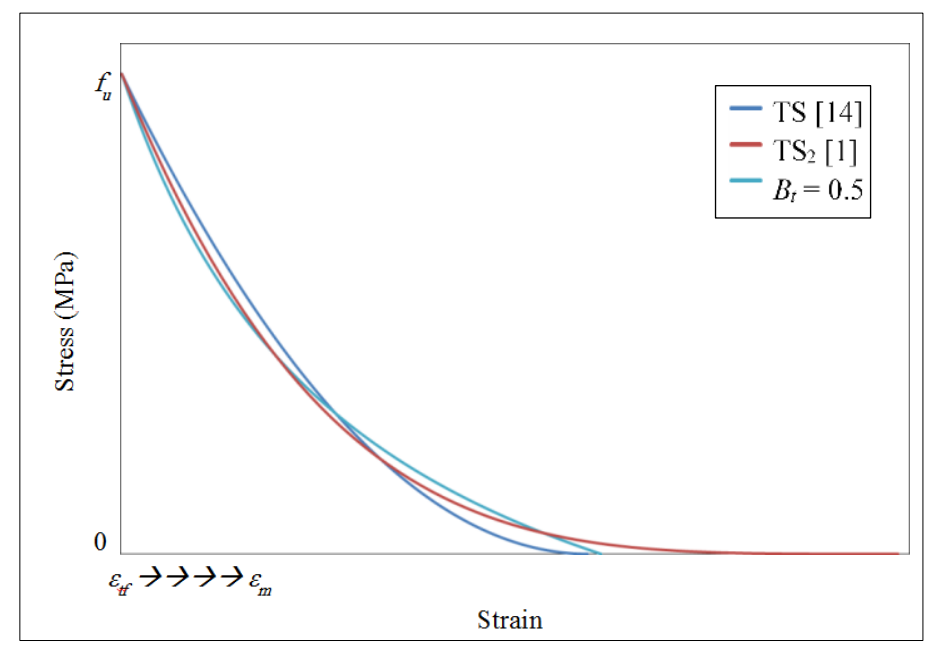

Figure 3 Comparison between the suggested model in this study and the previous models for tension stiffening of HSSFRC.

\section{CRACKED SHEAR MODULUS OF THE CONCRETE}

For shear modulus, a nonlinear equation is proposed to simulate the degradation of the cracked shear modulus. In some studies, it is suggested that the reduction of the cracked shear modulus 
is following a linear model and some of them suggested a nonlinear model. For the present study the same formula for tension stiffening is used for modelling the cracked shear modulus reduction but the curvature factor here called $\boldsymbol{B}_{g}$. The suggested equation is compared with the previous studies and a great agreement is achieved as shown in Figure 4.

The cracked shear modulus will be reduced gradually until it will reach the value of zero at the maximum tensile strain $\left(\varepsilon_{m}\right)$ and this value will be obtained from equation (11). Therefore, there is an interaction between tension stiffening and cracked shear modulus models.

$$
\begin{gathered}
\bar{G}=\mathrm{AG} \frac{B_{g}-\mathrm{B}_{g} * \mathrm{X}}{B_{g}+X} \\
X=\frac{\varepsilon_{i}-\varepsilon_{t f}}{\varepsilon_{m}-\varepsilon_{t f}}
\end{gathered}
$$

Where: A is the Ratio $(\bar{G} / G)$ at the beginning of the crack which is equal to 0.4 according to reference (Al-Mahaidi, 1978)

$\bar{G}, G$ is the shear modulus after and before crack respectively.

$B_{g}, v$ are the Curvature factor "shown in Figure 4" and Poisson's ratio respectively.

\section{STELL REINFORCEMENT MODELING}

The steel reinforcement is assumed as homogeneous material which mean that it has the same strength in compression and tension. The representation of the steel is done by using the smeared layer inside the concrete layers.

\section{FORMULATION OF THE FINITE ELEMENT}

The eight-node "isoparametric plate element (Ahmed element)" with three degrees of freedom at each node is adopted in this study. The formulation of this element is mentioned in reference (Hinton \& Owen, 1984). For steel reinforcement, a smeared layer method is adopted. Perfect bond (no slip between steel reinforcement and concrete) is assumed between the reinforcement and concrete. 


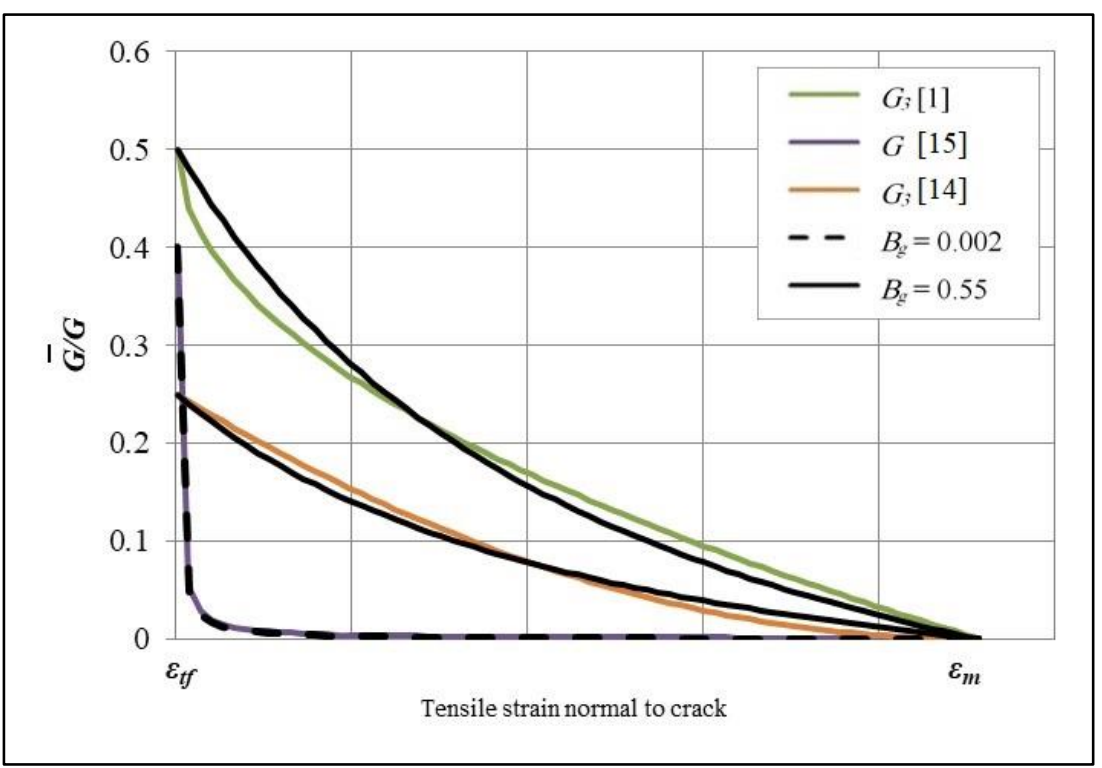

Figure 4 Comparison between the suggested model in this study and the models used in previous references for cracked shear modulus of HSSFRC.

\section{EXPERIMENTAL AND NUMERICAL RESULTS DESCRIPTION OF THE TESTED SLABS}

To complete the finite element analysis of the slabs and study the effect of cracked shear modul us and tension stiffening models. Many experimental tests of HSSFRC slabs in references (Alsinjari, 2014; Ragab, 2013; Yaseen, 2006; Zaki et al., 2013) are selected to compare them with the results of this study. The characteristics of the selected slabs are listed in Table 1. All studied slabs were simply supported from four sides and loaded with concentrated load at the middle of the slab, but slab S5 is simply supported by two opposite parallel sides with line load parallel to the supports at the middle of the span of the slab.

Table 1 the slabs properties

\begin{tabular}{|c|c|c|c|c|}
\hline Reference & $\begin{array}{c}(\mathrm{Al}- \\
\text { sinjari, } \\
2014)\end{array}$ & $\begin{array}{c}\text { (Yaseen, } \\
\text { 2006) }\end{array}$ & $\begin{array}{c}\text { (Ragab, } \\
2013 \text { ) }\end{array}$ & $\begin{array}{c}\text { (Zaki et } \\
\text { al., 2013) }\end{array}$ \\
\hline Slab number & S16 & $\mathrm{S} 42$ & S3 & S5 \\
\hline$V_{f} \%$ & 1.2 & 0.5 & 0.75 & 0.75 \\
\hline$l_{f} / d_{f}$ & 37 & 133 & 50 & 50 \\
\hline
\end{tabular}




\begin{tabular}{|c|c|c|c|c|c|}
\hline & $f_{c f}(\mathrm{MPa})$ & 59 & 50.8 & 55 & 71.15 \\
\cline { 2 - 5 } & $E_{c f}(\mathrm{GPa})$ & 38.91 & 36.13 & 37.56 & 42.73 \\
\hline$f_{t f}(\mathrm{MPa})$ & 6.8 & 4.77 & 5.5 & 6.79 \\
\hline$\varepsilon_{c u}\left(\mathrm{x} 10^{-3}\right)$ & 6.09 & 7.667 & 5.625 & 5.625 \\
\hline$f_{y}(\mathrm{MPa})$ & 614 & 670 & 360 & 670 \\
\hline$\rho_{x}, \rho_{y} \%$ & 1.8 & 1.5 & 0.8 & 0.687 \\
\hline $\begin{array}{c}\text { Dimensions of the slabs } \\
(\mathrm{m})\end{array}$ & $0.9 \mathrm{x} 0.9$ & $0.8 \mathrm{x} 0.8$ & $1.1 \mathrm{x} 1.1$ & $1.1 \times 1.1$ \\
\hline \begin{tabular}{c} 
Thickness of the slab $(\mathrm{mm})$ \\
\hline
\end{tabular} & 70 & 60 & 100 & 100 \\
\hline
\end{tabular}

$v=0.2, E_{s}=200000 \mathrm{MPa}$.

\section{MODELLING THE FINITE ELEMENT}

A computer program coded in Fortran 90 was implemented for nonlinear analysis of HSSFRC slabs using finite element method. All the proposed models in this study are used in this program. Because the slabs are symmetric, one quarter of the slabs was modeled using 16 elements. Reduced integration rule ( $2 \times 2$ Gauss points) is used.

\section{ANALYSIS OF THE RESULTS}

In the present study, many shapes of cracked shear modulus and tension stiffening models are used and the values of $B_{g}$ are $\left(0.005,0.05,0.5\right.$ and 1.0) and the values of $B_{t}$ are $(0.005,0.05,0.1$ and 0.5 ) as shown in Figure 2 and these values cover large possible shapes of these relations. The load deflection curves for this study using these models of cracked shear modulus and tension stiffening are compared with the actual results from experimental tests as shown in the following figures. 

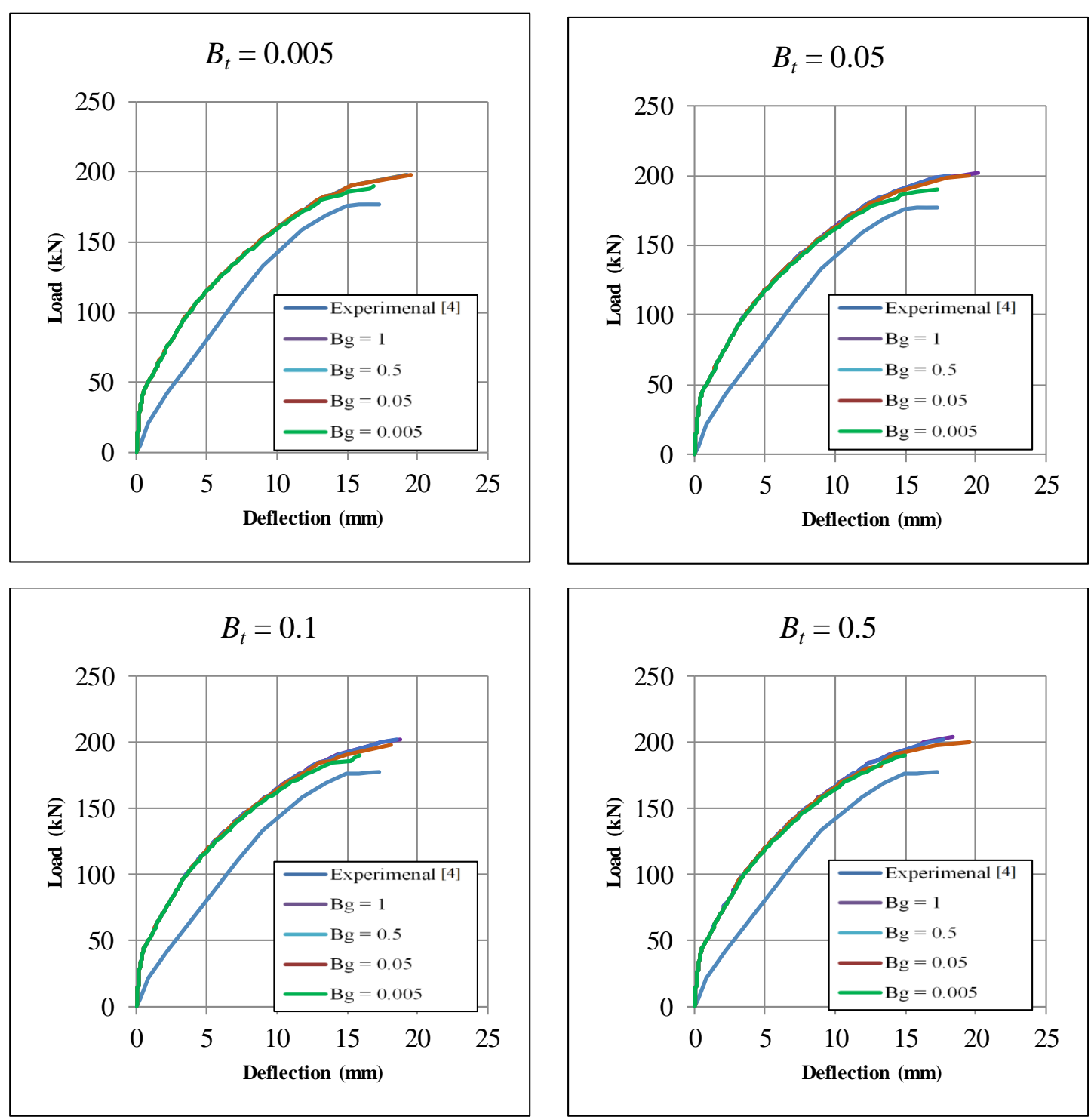

Figure 5 Comparison between load deflection curves from this study with experimental load deflection curve for slab S16.
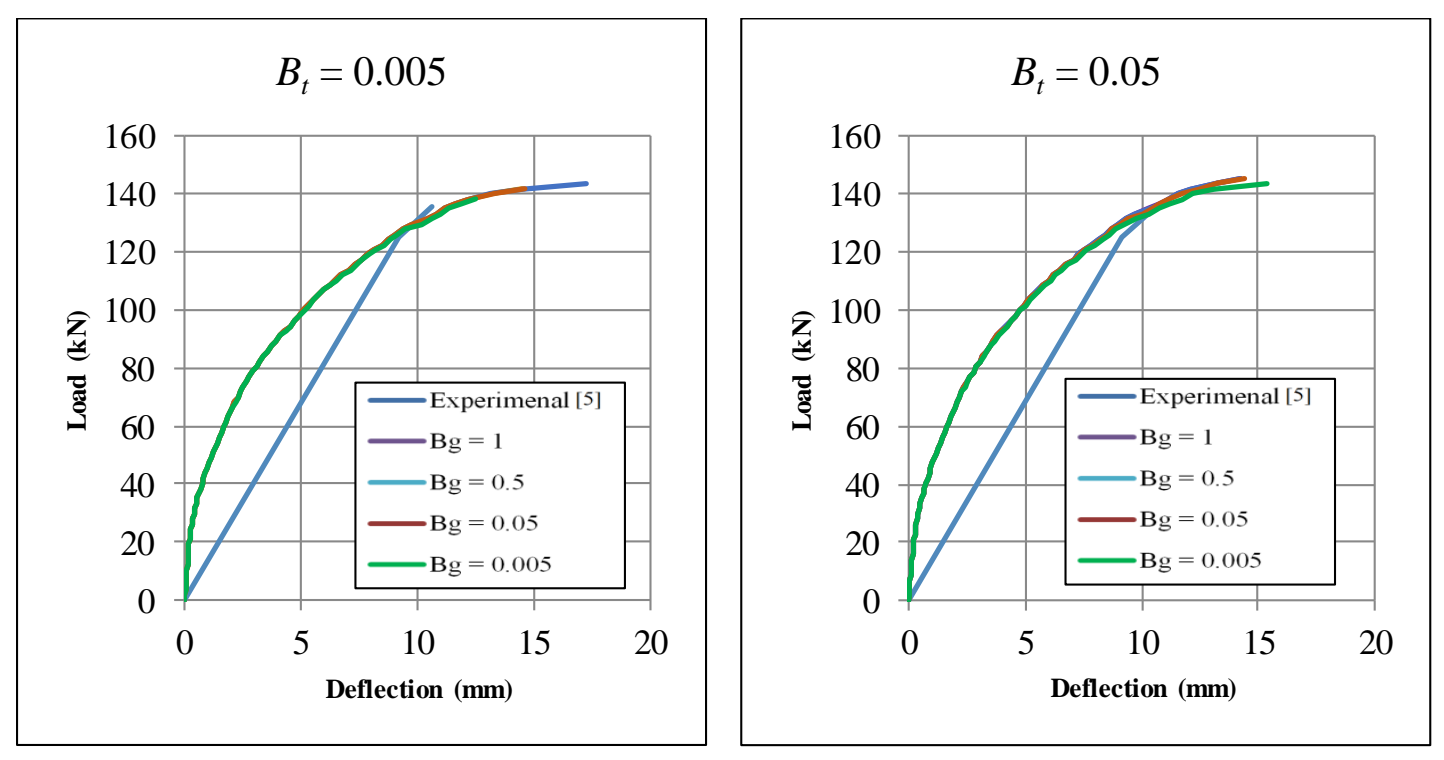

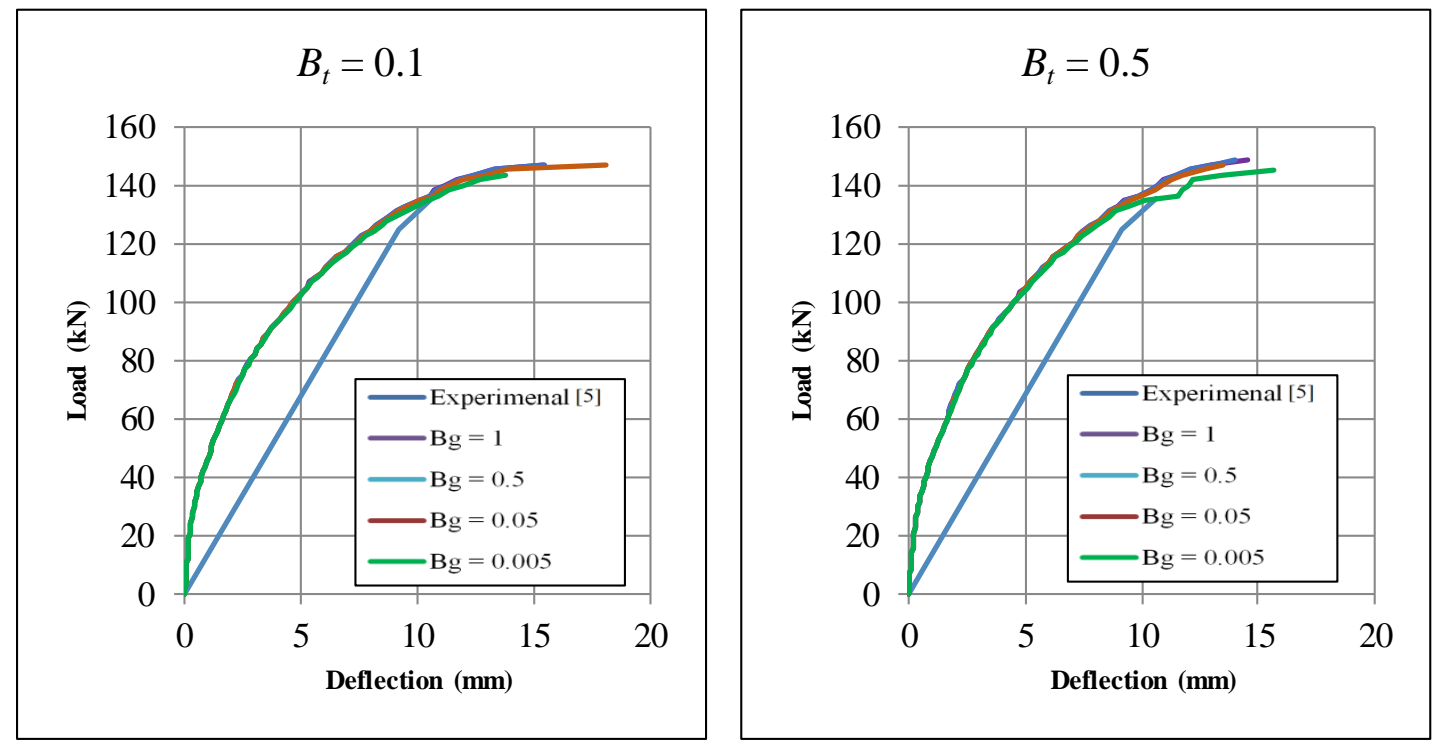

Figure 6 Comparison between load deflection curves from this study with experimental load deflection curve for slab S42.
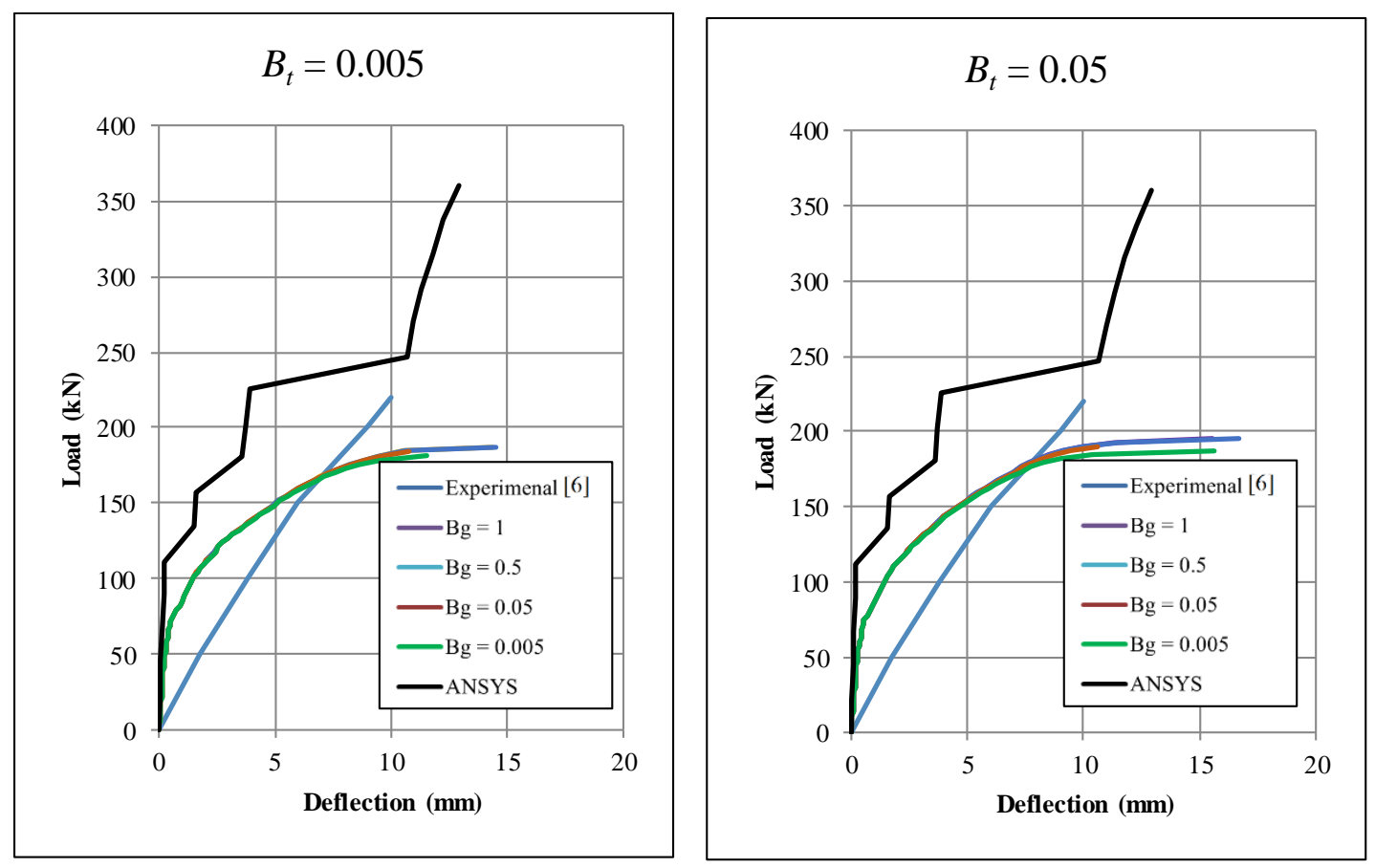

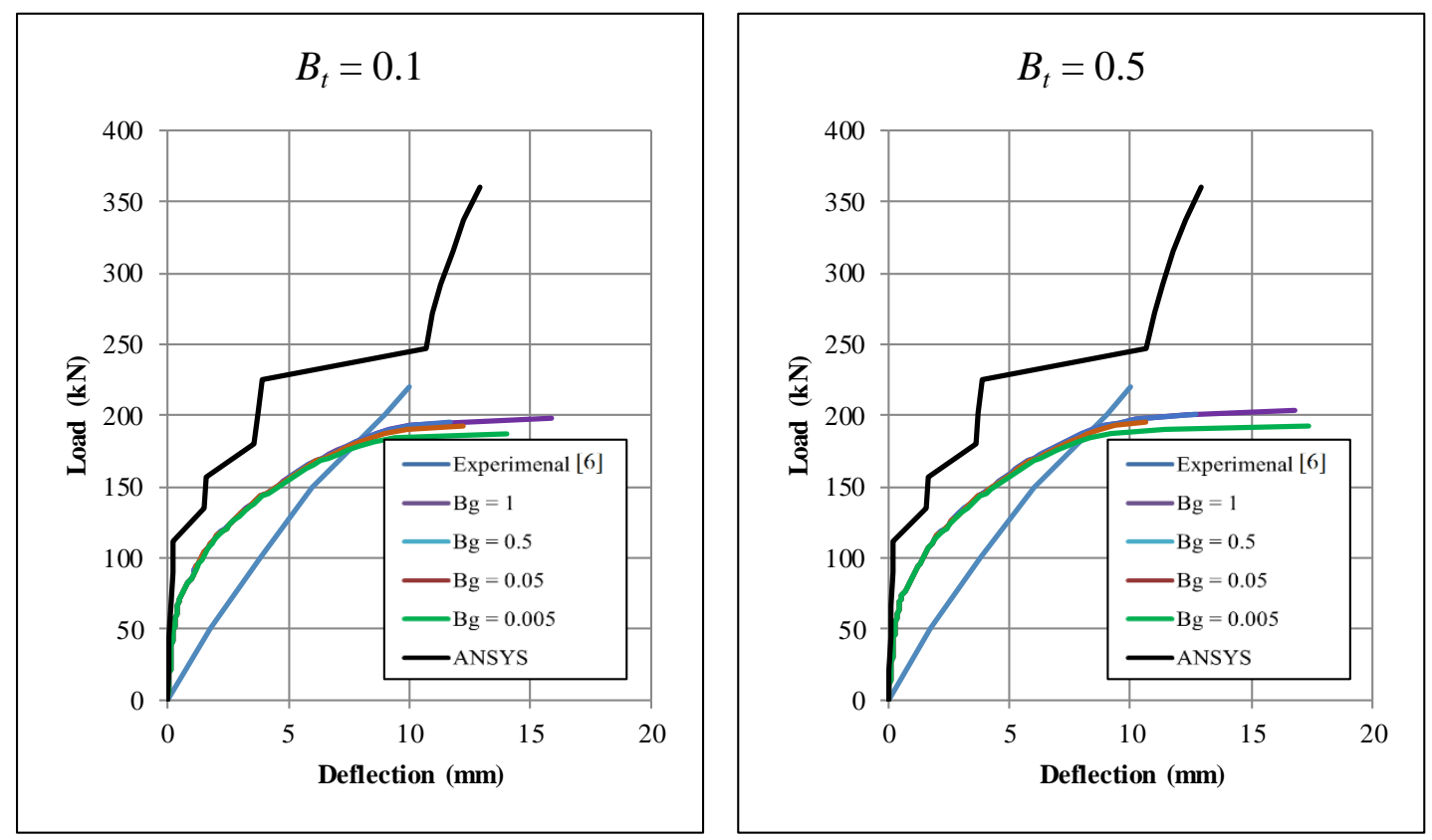

Figure 7 Comparison between load deflection curves from this study with experimental load deflection curve for slab S3.
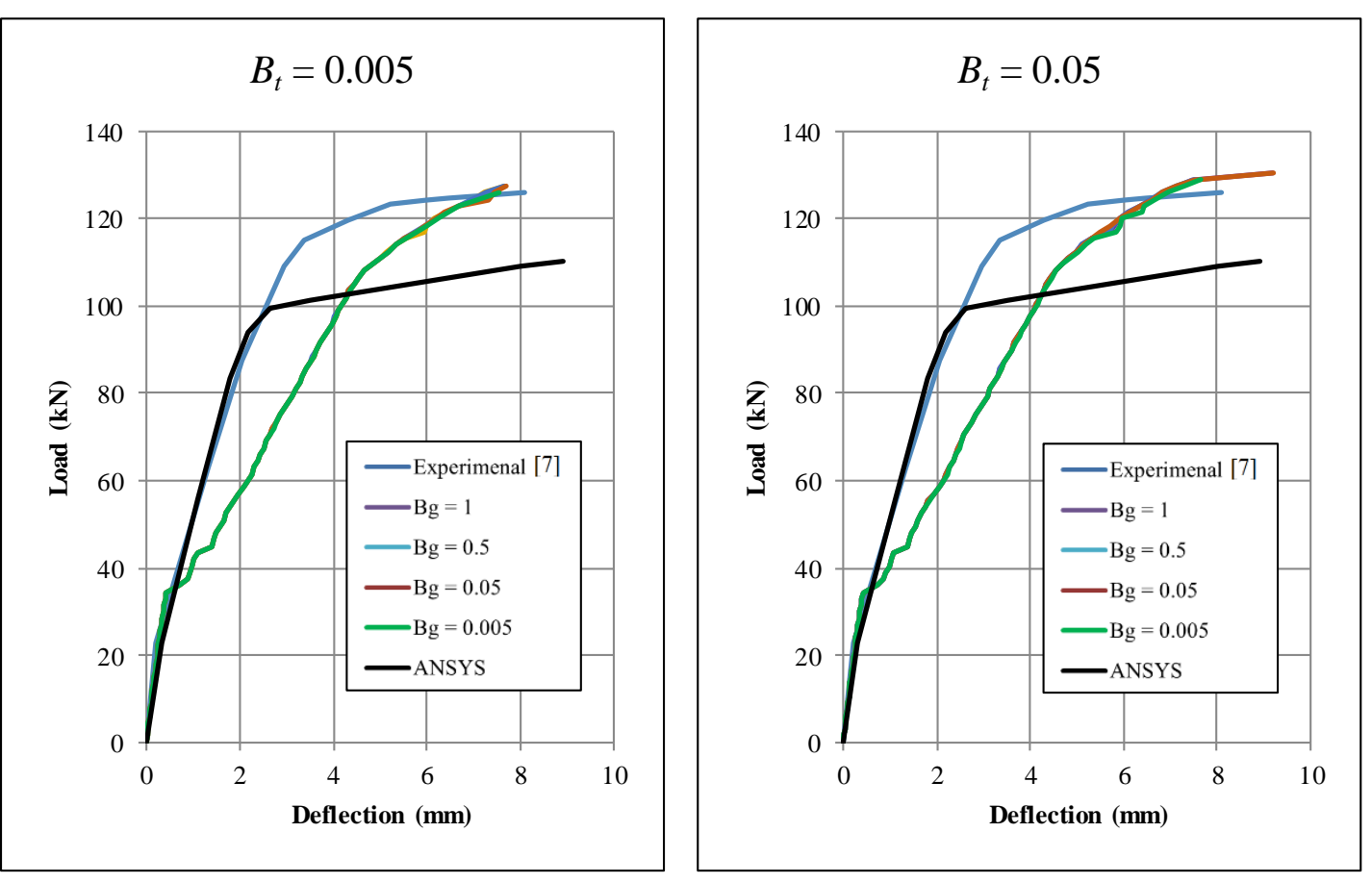

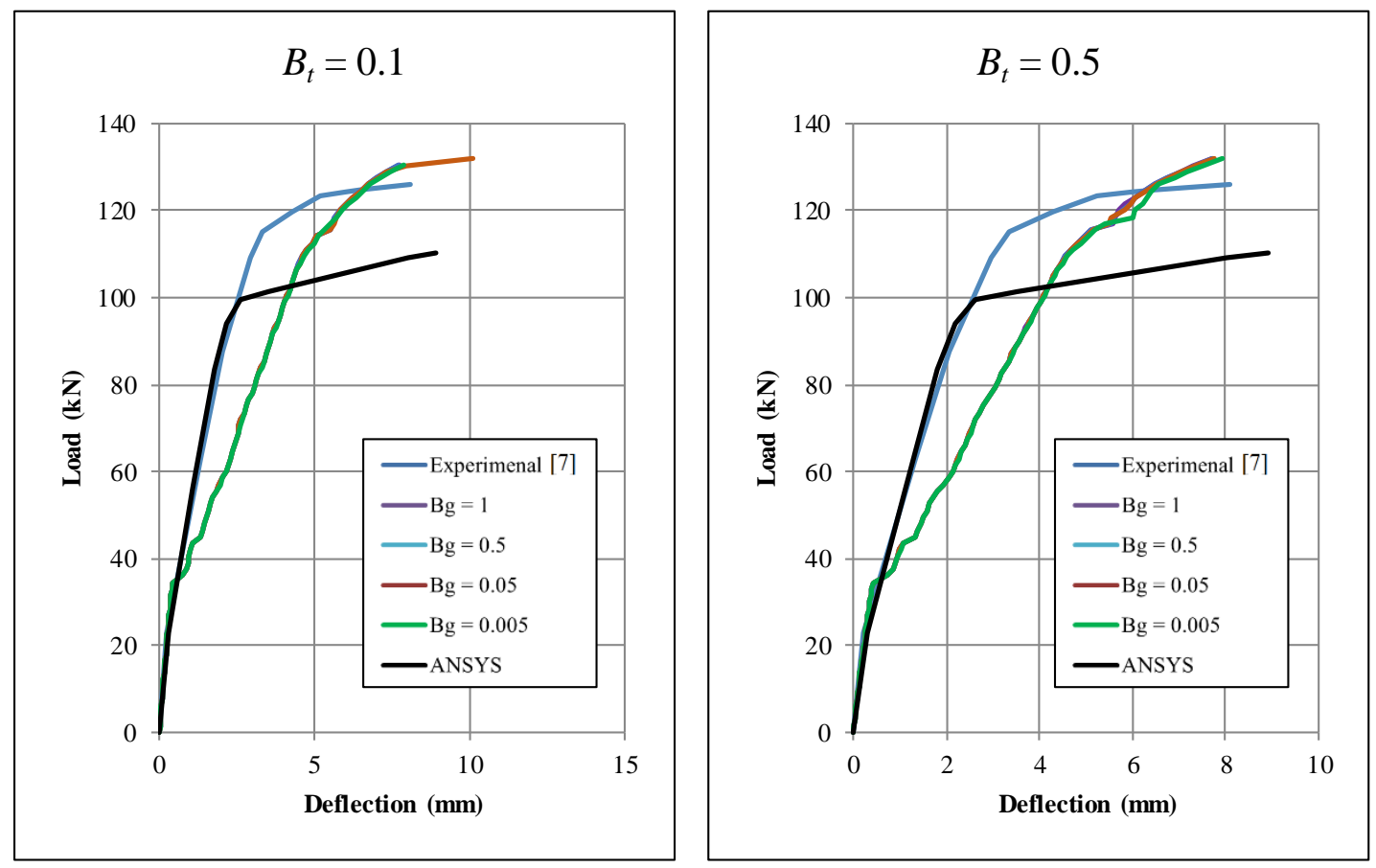

Figure 8 Comparison between load deflection curves from this study with experimental load deflection curve for slab S5.

From figures (5-8) it is found that there is good agreement in comparison between the numerical and experimental load deflection curves. From these figures, it is clear that the shape of the

relation of the cracked shear modulus and tension stiffening models has an important effect on the response of the concrete slabs. The factors $\left(B_{g}\right.$ and $\left.B_{t}\right)$ is responsible for the curvature of the curves, so by reducing these factors the curves are converted to very sharp curvature and the stiffness of the slabs will reduced. The effect of the tension-stiffening model is more than the effect of cracked shear modulus on the slab, and that is because the slab is subjected to bending stresses more than shear stresses.

From the previous figures, it is found that there is an interaction between the tension stiffening and the cracked shear modulus models. By changing the value of $B_{t}$ the value of $\varepsilon_{m}$ will change too to keep a constant value of $G_{F}$ (which is the area under the stress strain curve in tension) as shown in Figure 2, and by changing the value of $\varepsilon_{m}$ the shape of the reduced shear modulus relation will change too. 
The crack pattern of the slabs in the present study for (S42 and S5) at the failure load showed great agreement with the actual crack patterns as shown in Figure 9 and Figure 10.
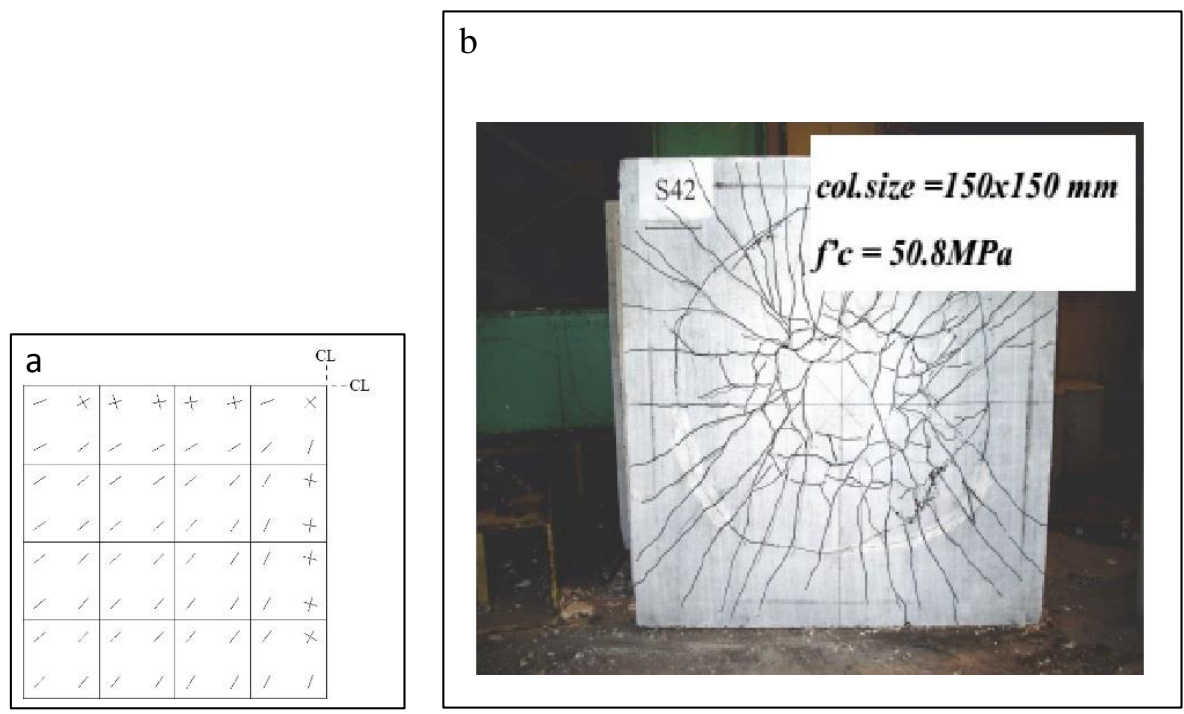

Figure 9 a) Crack pattern for one quarter of S42 in this study. b) Experimental crack pattern for S42 (Yaseen, 2006)
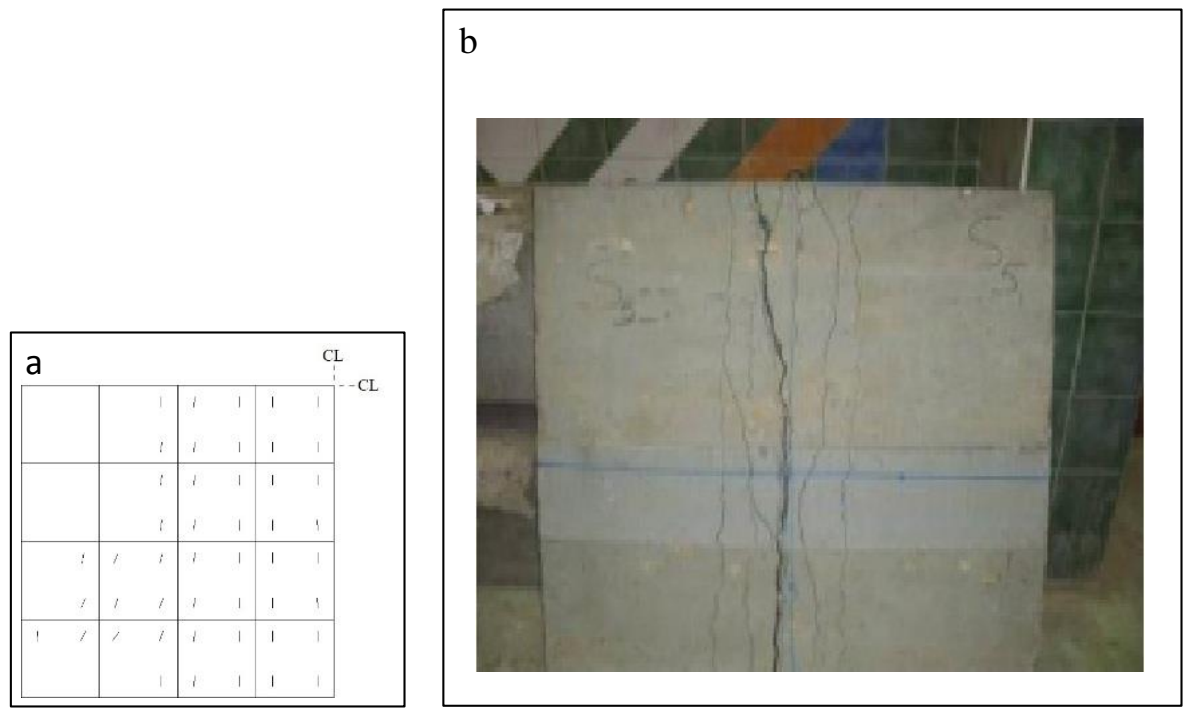

Figure 10 a) Crack pattern for one quarter of S5 in this study. b) Experimental crack pattern for S5 (Zaki et al., 2013)

In S42, the location and direction of the cracks is very similar to the actual crack pattern and the cracks direction is distributed in radial mode. In the corners, the direction of cracks is about 450 as assumed in the yield line analysis. For slab S5 the direction of the cracks in the middle of the slab are parallel to the supports as expected. 
The ultimate load is one of the most important property of the slab, so the values of the ultimate load for the all proposed models used in this study are showed in Table 2.

Table 2 Failure load of slabs from this study and experimental test

\begin{tabular}{|c|c|c|c|c|c|c|c|c|c|c|c|}
\hline $\begin{array}{c}\text { Slab } \\
\text { identification }\end{array}$ & $B_{t}$ & $B g$ & $\begin{array}{c}P_{\mathrm{u}} \text { test } \\
(\mathrm{kN})\end{array}$ & $\begin{array}{c}\mathrm{P}_{\mathrm{u}} \exp . \\
(\mathrm{kN})\end{array}$ & $\begin{array}{l}P_{u} \text { test/ } \\
P_{u} \text { exp. }\end{array}$ & $\begin{array}{c}\text { Slab } \\
\text { identification }\end{array}$ & $B_{t}$ & $B g$ & $\begin{array}{c}P_{\mathrm{u}} \text { test } \\
(\mathrm{kN})\end{array}$ & $\begin{array}{l}\mathrm{P}_{\mathrm{u}} \\
\text { exp. } \\
(\mathrm{kN})\end{array}$ & $\begin{array}{l}\mathrm{P}_{\mathrm{u}} \text { test/ } \\
\mathrm{P}_{\mathrm{u}} \text { exp. }\end{array}$ \\
\hline & 0.005 & 1 & 198 & 176.8 & 1.1199 & & 0.005 & 1 & 187 & 220 & 0.85 \\
\hline & 0.005 & 0.5 & 198 & 176.8 & 1.1199 & & 0.005 & 0.5 & 187 & 220 & 0.85 \\
\hline & 0.005 & 0.05 & 198 & 176.8 & 1.1199 & & 0.005 & 0.05 & 184.25 & 220 & 0.8375 \\
\hline & 0.005 & 0.005 & 190 & 176.8 & 1.0747 & & 0.005 & 0.005 & 181.5 & 220 & 0.825 \\
\hline & 0.05 & 1 & 202 & 176.8 & 1.1425 & & 0.05 & 1 & 195.25 & 220 & 0.8875 \\
\hline & 0.05 & 0.5 & 200 & 176.8 & 1.1312 & & 0.05 & 0.5 & 195.25 & 220 & 0.8875 \\
\hline & 0.05 & 0.05 & 200 & 176.8 & 1.1312 & & 0.05 & 0.05 & 189.75 & 220 & 0.8625 \\
\hline & 0.05 & 0.005 & 190 & 176.8 & 1.0747 & & 0.05 & 0.005 & 187 & 220 & 0.85 \\
\hline & 0.1 & 1 & 202 & 176.8 & 1.1425 & & 0.1 & 1 & 198 & 220 & 0.9 \\
\hline & 0.1 & 0.5 & 202 & 176.8 & 1.1425 & & 0.1 & 0.5 & 195.25 & 220 & 0.8875 \\
\hline & 0.1 & 0.05 & 198 & 176.8 & 1.1199 & & 0.1 & 0.05 & 192.5 & 220 & 0.875 \\
\hline & 0.1 & 0.005 & 190 & 176.8 & 1.0747 & & 0.1 & 0.005 & 187 & 220 & 0.85 \\
\hline & 0.5 & 1 & 204 & 176.8 & 1.1538 & & 0.5 & 1 & 203.5 & 220 & 0.925 \\
\hline & 0.5 & 0.5 & 202 & 176.8 & 1.1425 & & 0.5 & 0.5 & 200.75 & 220 & 0.9125 \\
\hline & 0.5 & 0.05 & 200 & 176.8 & 1.1312 & & 0.5 & 0.05 & 195.25 & 220 & 0.8875 \\
\hline & 0.5 & 0.005 & 190 & 176.8 & 1.0747 & & 0.5 & 0.005 & 192.5 & 220 & 0.875 \\
\hline & 0.005 & 1 & 141.75 & 135.5 & 1.0461 & & 0.005 & 1 & 127.5 & 126 & 1.0119 \\
\hline & 0.005 & 0.5 & 143.5 & 135.5 & 1.0590 & & 0.005 & 0.5 & 127.5 & 126 & 1.0119 \\
\hline & 0.005 & 0.05 & 141.75 & 135.5 & 1.0461 & & 0.005 & 0.05 & 127.5 & 126 & 1.0119 \\
\hline & 0.005 & 0.005 & 138.25 & 135.5 & 1.0203 & & 0.005 & 0.005 & 126 & 126 & 1.0000 \\
\hline & 0.05 & 1 & 145.25 & 135.5 & 1.0719 & & 0.05 & 1 & 130.5 & 126 & 1.0357 \\
\hline & 0.05 & 0.5 & 145.25 & 135.5 & 1.0719 & & 0.05 & 0.5 & 129 & 126 & 1.0238 \\
\hline & 0.05 & 0.05 & 145.25 & 135.5 & 1.0719 & & 0.05 & 0.05 & 130.5 & 126 & 1.0357 \\
\hline & 0.05 & 0.005 & 143.5 & 135.5 & 1.0590 & & 0.05 & 0.005 & 129 & 126 & 1.0238 \\
\hline & 0.1 & 1 & 147 & 135.5 & 1.0848 & & 0.1 & 1 & 130.5 & 126 & 1.0357 \\
\hline & 0.1 & 0.5 & 147 & 135.5 & 1.0848 & & 0.1 & 0.5 & 130.5 & 126 & 1.0357 \\
\hline & 0.1 & 0.05 & 147 & 135.5 & 1.0848 & & 0.1 & 0.05 & 132 & 126 & 1.0476 \\
\hline & 0.1 & 0.005 & 143.5 & 135.5 & 1.0590 & & 0.1 & 0.005 & 130.5 & 126 & 1.0357 \\
\hline & 0.5 & 1 & 148.75 & 135.5 & 1.0977 & & 0.5 & 1 & 132 & 126 & 1.0476 \\
\hline & 0.5 & 0.5 & 148.75 & 135.5 & 1.0977 & & 0.5 & 0.5 & 132 & 126 & 1.0476 \\
\hline & 0.5 & 0.05 & 147 & 135.5 & 1.0848 & & 0.5 & 0.05 & 132 & 126 & 1.0476 \\
\hline & 0.5 & 0.005 & 145.25 & 135.5 & 1.0719 & & 0.5 & 0.005 & 132 & 126 & 1.0476 \\
\hline
\end{tabular}




\section{CONCLUSIONS}

- The eight-node plate element with $3 \mathrm{DoF}$ at each node approved to be valid and useful for nonlinear analysis of high strength steel fiber reinforced concrete slabs.

- Reduced integration (2x2 gauss points) is used and no shear locking and spurious modes detected.

- The smeared layer is adopted to simulate the steel reinforcement and this method approved to be used in the nonlinear finite element analysis.

- For the ultimate failure load, excellent agreement is achieved in comparison between the results of the present study and the actual experimental results for all slabs as listed in Table 2. For slabs (S3 and S5), the results of the ultimate load of this study are better than the results obtained from ANSYS program.

- The cracked shear modulus and tension stiffening models (values of $B_{g}$ and $B_{t}$ ) have an important effect on the response of the HSSFRC slabs. As the values of $B_{g}$ and $B_{t}$ reduced the slab stiffness reduced. For the curvature factors $\left(B_{g}-B_{t}\right)$ the best values for them are $(\mathrm{Bt}$ $=0.005-0.5, \mathrm{Bg}=0.001-0.05)$.

- The effect of tension stiffening model is more than the effect of cracked shear modulus model on the nonlinear analysis of the slabs.

- There is an interaction between tension stiffening and cracked shear modulus models, and the value of $G_{F}$ is the controlling factor of that interaction, so the value of the fracture energy is a very important factor and its model should be taken carefully.

- The proposed constitutive models are succeeded to simulate the HSSFRC slabs. 


\section{REFERENCES}

Abbass, W., M.I. Khan, and S. Mourad, (2018), "Evaluation of mechanical properties of steel fiber reinforced concrete with different strengths of concrete". Construction and Building Materials, 168, pp: 556-569.

Abdul-Razzak, A.A., (1996), Nonlinear Finite Element Analysis of Fibrous Reinforced Concrete Structural Members, PhD Dissertation, University of Mosul.

Abdul-Razzak, A.A. and A.A.-J. Mohammed, (2011), "Modelling and Numerical Simulation of High Strength Fibre Reinforced Concrete Corbels". Applied Mathematical Modelling, Vol. 35: p. 2901-2915.

Al-Mahaidi, R.S.H., (1978), Nonlinear Finite Element Analysis of Reinforced Concrete Deep Members, Cornell University, New York.

Al-Sinjari, A.M.S., (2014), "Punching Shear Resistance of Self Compacting Flat Slabs Reinforced with Steel Fibers", MSc Thesis, University of Mosul.

Hinton, E. and D.R.J. Owen, (1984), Finite Element Software for Plates and Shells, Pineridge Press Limited, Swansea, UK.

Koksal, F., Altun, F., Yigit, I., Sahin, Y., (2008), “Combined Effect of Silica Fume and Steel Fiber on the Mechanical Properties of High Strength Concretes". Construction and Building Materials, Vol. 22, pp: 1874-1880.

Lee., S.C., J.H. Oh., and J.Y. Cho., (2015), “Compressive Behavior of Fiber-Reinforced Concrete with End-Hooked Steel Fibers". Materials, Vol. 8, pp: 1442-1458.

Lin, W, T., Huang, R., Lee, C, L., Hsu, H, M., (2008), "Effect of Steel Fiber on the Mechanical Properties of Cement Based Composites Containing Silica Fume". Journal of Marine Science and Technology, Vol. 16, No. 3, pp: 214-221.

Mohammed, A.A., (2011), "Nonlinear Analysis of High Strength Fibrous Reinforced Concrete Corbels Using Plane Stress Element", M.Sc. thesis in Civil Engineering, University of Mosul: Iraq. 
Musmar, M.A. and M.I. Rjoub, (2007), “A Mathematical Expression for Split Tensile Strength of Steel Fiber Reinforced Concrete". Journal of Engineering Sciences, Vol. 35, No. 2, pp: 323-335.

Ragab, K.S., (2013), "Study Punching Shear of Steel Fiber Reinforced Self Compacting Concrete Slabs by Nonlinear Analysis". International Journal of Civil, Structural, Construction and Architectural Engineering. Vol. 7, No. 9, pp: 288-299.

Song, P.S. and S. Hwang, (2004), "Mechanical Properties of High Strength Steel Fiber Reinforced Concrete”. Construction and Building Materials, Vol. 18, pp: 669-673.

Yaseen, A.A., (2006), Punching Shear Strength of Steel Fiber High Strength Reinforced Concrete Slabs, MSc Thesis, University of Portsmouth.

Zaki, S.I., K.S. Ragab, and A.S. Eisa, (2013), "Flexural Behaviour of Steel Fibers Reinforced High Strength Self Compacting Concrete Slabs". International Journal of Engineering Inventions, Vol. 2, No. 5, pp: 1-11. 